\title{
"Something We Loved That Was Taken Away": Community and Neoliberalism in World of Warcraft
}

\author{
Nicole Crenshaw \\ University of California, \\ Irvine \\ Irvine, CA 92697 USA \\ crenshan@uci.edu
}

\author{
Jaclyn LaMorte \\ University of California, \\ Irvine \\ Irvine, CA 92697 USA \\ jlamorte@uci.edu
}

\author{
Bonnie Nardi \\ University of California, \\ Irvine \\ Irvine, CA 92697 USA \\ nardi@uci.edu
}

\begin{abstract}
In this paper, we explore social life and play experiences on Nostalrius Begins, a World of Warcraft (WoW) private server. Private servers allow players to return to previous versions of a game before changes that modified it. Research indicates that changes to the current version of WoW discourage sociality and are upsetting for many players. Through a year-long ethnography, we found that the stories, memories, struggles, and concerns that players shared on Nostalrius Begins allowed them to rebuild the social community that they missed from earlier versions of the game. Over time, however, the neoliberal ideology of offline culture influenced players' behaviors and affected social experience in a different way. Our research provides an analysis of the tension between community and neoliberal values in online games.
\end{abstract}

\section{Introduction}

Despite the countless hours people spend in online games, we do not yet fully understand their social and cultural significance. World of Warcraft (WoW), one of the largest and longest running massively multiplayer online games, has significantly influenced society, forever changing game culture, game studies, and the game industry.

Since its release in 2004, Blizzard Entertainment, the maker of the game, has periodically changed WoW. Small software "patches" and major "expansions" have altered the play experience to varying degrees, such as reducing the difficulty in play or the time required to play $[4,8,28]$. While these changes have been appealing to some, they have often minimized the need to interact and collaborate with other people, making the game less social. Clearly, the technological affordances of the game impact social life $[4,8,32,43]$. However, affordances do not determine online social interactions by themselves. People embody the values of their culture through their online activities $[13,25,44]$. We argue that social experience in online venues is a product of two factors: the affordances of the technology and the influence of the culture in which the technology is created and used. We must examine both a game's design and the cultural setting to explain the social experiences it produces.

Some research still locates vibrant communities in games such as EVE Online [2,21] and (the now defunct) Faunasphere [6,7]. However, research on World of Warcraft indicates that "solo-play" has become more common, and is often encouraged by the game's current design [4,8,32]. O'Connor et al. [32] found that an increase in solo-play could be traced to changes in game mechanics that no longer reward or require players to cooperate. Crenshaw and Nardi [8] demonstrated how changes to game mechanics reduce social interaction, even in situations where players collaborate or inhabit the same area of the game. Braithwaite [4] argued, even more emphatically, that changes in WoW's design encourage players to see one another as obstacles or agents with whom to compete, rather than potential collaborators. Overall, these changes have altered the social experience and reduced the sense of community in World of Warcraft. Instead, the current version of the game favors a more entrepreneurial and individualistic subjectivity.

We build on the work of scholars such as Braithwaite [4] and Dyer-Witheford and de Peuter [14], who have explored how neoliberal values inform game design. We argue that the ways that WoW players behave has changed since the game's release in 2004 , becoming increasingly influenced by a neoliberal ideology that values competition and individualistic self-interest over community. How have these changes to the game design and game play changed players' World of Warcraft experiences? 
To answer this question, we move away from Blizzard's version of World of Warcraft to a different venue in which WoW is played, i.e., a private server. A private server allows people to host their own version of a game by using a game's proprietary software (some of which is cached on the user's own machine) combined with newly developed code $[10,45]$. People can play the game it emulates for free (although this arrangement is a breach of intellectual property rights). To avoid copyright laws, most private server administrators host their servers in Europe or Asia where it is harder to punish violations of US laws. Private servers are generally created and managed by small, committed development teams that spend long hours coding, scripting, and debugging their servers to provide smooth play for their communities [10]. WoW private servers have existed for years, but have become more popular and technologically refined recently [45].

Some players choose private servers that offer ways to play WoW that are more like earlier versions of the game. In particular, "Vanilla" severs have seen a rise in popularity [45]. Vanilla refers to the original World of Warcraft game, prior to any expansions, which many players remember fondly [29,32]. What is it about this golden age of World of Warcraft that resonates with players? And is it possible to recreate that experience? To consider these questions, we analyze social life on the popular private server Nostalrius Begins.

\section{Background}

WoW is undoubtedly one of the most famous online games $[4,11,12,28,29,30,32,38,43]$. At its zenith in 2012, it had over 12 million subscribers worldwide. The population fluctuates, but Blizzard's 2015 Q3 report stated that 5.5 million people had WoW subscriptions [48]. Blizzard has since stopped making WoW's subscription numbers publicly available. It is likely that subscriptions continue to decline (although the current expansion, released at the end of August, likely increased numbers again, as typically happens).

World of Warcraft is a 3D medieval fantasy game that takes players to the world of Azeroth. Players create characters who slay monsters, collect resources such as cloth and ore, hone crafts such as alchemy and leatherworking, engage in an economy by selling items with game currency to other players, and participate in trade transactions where they can exchange goods and services [29]. Some players join relatively stable "guilds" in which a group of people can play and chat together regularly $[29,32,33,35,36,43]$. Players work together to progress through game content such as "dungeons," i.e., activities that require the collaboration of five players and may take quite a while to complete, and "raids" that require 10-40 players. Players challenge strong enemies known as "bosses" that provide special rewards for players once defeated. Players use their characters to progress through a series of themed areas such as dank swamps, humid jungles, and frozen tundras. By completing "quests" (narrativized tasks) in each area, players reach higher "levels" and encounter greater challenges. The newest World of Warcraft expansion, Legion (August 2016), has raised the maximum level to 110 .

We have chosen a World of Warcraft private server as a field site for several reasons. First, WoW is one of the most studied games in the academic literature, providing a solid basis for evaluating changes in player behavior $\quad[1,4,8,9,11,14,29,30,32,33,38,39,43,46,47]$. Second, changes to World of Warcraft's software are documented through Blizzard's official patch notes, forum discussions, and wiki sites. This extensive documentation makes it possible to determine when Blizzard implemented particular changes, when player reactions to the events began, and whether Blizzard further modified the game after player feedback. Third, the paratextual activity that mediates and informs game play in WoW is more extensive and visible than other, similar games. Facebook groups, fan forums, and the annual BlizzCon Conference in Anaheim, California, all contribute to the World of Warcraft community.

\subsection{Nostalrius Begins}

Nostalrius Begins, or just Nostalrius, was a private server based in France. It appealed to players' nostalgia for Vanilla WoW by recreating a "Blizz-like," game, as close to the original version as possible, with nearly identical game geographies, content release timelines, and patches as "retail WoW," or Blizzard's official version of the game. Nostalrius' home page, lauding "the glory days of World of Warcraft" (Figure 1), suggests that something about this version of the game was special for players.

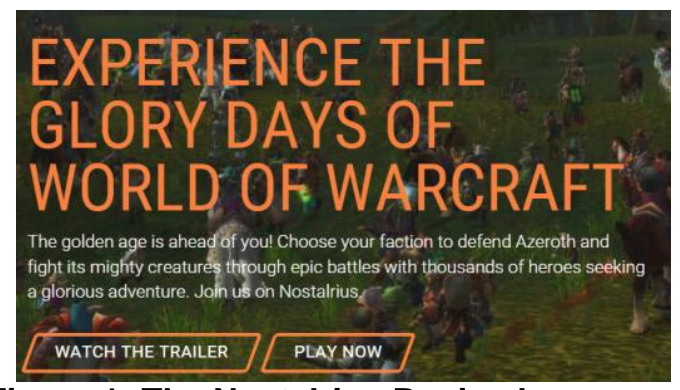

Figure 1: The Nostalrius Begins homepage.

While private servers, and more specifically, Vanilla private servers, cater to a particular kind of audience, i.e., veteran players who may be nostalgic, 
many players were not there for nostalgia. For example, teenage players who were not old enough to have played Vanilla WoW, players who had never played a particular class in Vanilla WoW, or players who had not experienced particular dungeons or boss fights, played on Nostralrius. While grizzled gaming veterans were present, there were many players looking to experience what Nostalrius offered for the very first time.

\subsection{RealmPlayers}

Sometimes, gamers use "mods" or "add-ons" to alter their play experience by modifying the game. Scholars have explored the use of mods in World of Warcraft to help players perform better, change the functionality of the game, and improve the overall play experience [15,26,29,31,37].

One mod popular on Nostalrius was "RealmPlayers," a third-party site created for WoW private servers. It aggregates data and metrics for ingame activities, such as how much "damage" or "healing" a character does, from players running the RealmPlayers application [49]. While some metric tracking was available in retail Vanilla WoW, the level of detail in RealmPlayers was not possible in 2004. Dilatazu, the online handle of the creator of RealmPlayers, works from donations and volunteer labor from other players. After downloading the RealmPlayers application, players record information about the characters they interact with in-game. Once the player exits the game, RealmPlayers uploads the information to the RealmPlayers server. Nostalrius was one of about 20 private servers for which data can be recorded.

Data on RealmPlayers includes character information (e.g., Name, Guild, Level, Race, Class), gear information (e.g., Weapons, Armor), guild information (e.g., Name, Raid Progress, Members), raid information (e.g., Start Time, End Time, Damage Dealt, Healing Dealt), and guild records per boss fight (e.g., Top Damage Per Second, Top Healing Per Second). Using this information, RealmPlayers generates a leader board for each server that ranks all players along different dimensions, such as character type and activity. Players and guilds can find their data on the RealmPlayers website, and use it to analyze the efficiency and effectiveness of their play in comparison to their guildmates and to other players on their server.

Many Nostalrius players used RealmPlayers to determine the success of guilds and the skill of players. Figure 2 shows a sample "damage meter" for a boss fight. Each colored line denotes a different character, and how much damage they did during the fight. We will discuss how this tool was used.

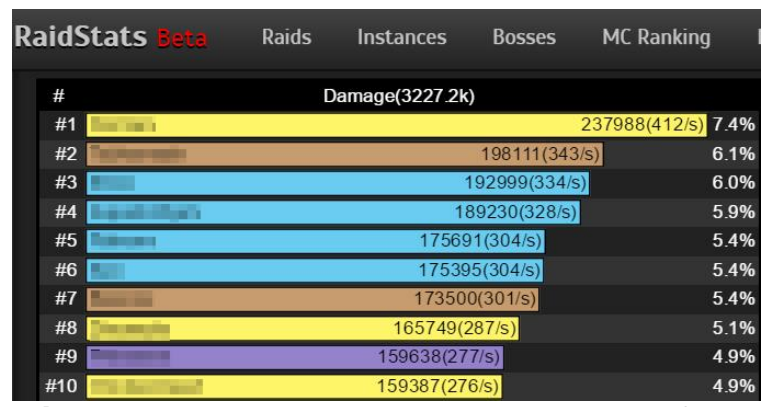

Figure 2: RealmPlayers damage meters for a boss fight.

\section{Theory}

We analyze game play in terms of neoliberal ideology. The concept of neoliberalism can be traced back to Milton Friedman's book, Capitalism and Freedom [23]. Friedman emphasized limited governmental scope, dispersed governmental power, and the preservation of individual freedoms by limiting and decentralizing bureaucracy. He claimed that a true liberal person is economically and politically free and lives in a society with limited governmental power. (When Friedman said "liberal," he meant what we currently understand as "neoliberal.")

Researchers have analyzed the effects of the neoliberal ideology on social interactions for diverse arenas pertinent to computing, including electronic medical records [15], crowdsourcing [24], digital games $[4,14,15]$, and changes in wider society $[5,22,34,40]$. For example, Ekbia and Nardi [15,16] examined ethical problems in "technologies of heteromation," where human labor is treated, rewarded, and compensated as if it were produced by machines, rather than fully-realized human agents.

Though many game studies researchers do not frame their analyses with the lens of neoliberalism, some scholars have reported player behaviors that contribute to the individualistic, economic ethos crucial to neoliberalism. Taylor et al. [42] showed that players provide free labor to game companies through the simple act of playing. By populating the game world, participating in the in-game economy, and interacting with others, players contribute to a company's financial capital. Dyer-Witheford and de Peuter [14] documented practices in WoW that contribute to "neoliberal regimes...on a planetary scale," including gold farming (turning in-game currency to currencies such as the US dollar), "grinding," i.e., repetitive, factory-like actions in-game, and the inability to "win" the game. Paul and Philpott [33] documented social life in a guild where an increasing focus on the allocation of scarce resources (e.g., spots for in-game activities and rare weapons), created a competitive atmosphere 
that eventually led to the guild's demise. Silverman and Simon [39] examined guilds' use of incentives in raids. Rewarding players with an unofficial, nonmonetary currency, guilds tried to increase individual participation in raids, and increase individual loyalty to the guild.

Many contemporary scholars have criticized neoliberal theory. For example, political scientist Wendy Brown argues that neoliberal societies overwhelmingly dictate that all conduct is economic in nature: "[A]ll spheres of existence are framed and measured by economic terms and metrics, even when those spheres are not directly monetized" [5]. In a neoliberal society, "How does this interaction benefit ME?" becomes a central motivating question for determining what to do and with whom to do it. In societies that subscribe to a neoliberal ideology, people are "competing with, rather than exchanging with each other" [5]. The shift from cooperation to competition has several serious effects on cultural development.

Brown [5] argues that a neoliberal ideology tends to have four harmful cultural effects. The first is intensified inequality, where the small, top social class accumulates and maintains more wealth than the larger middle and lower classes. These classes continue to work for fewer benefits, less security, and fewer opportunities for upward mobility. The second effect is that neoliberalism encourages unethical commercialization of things that society would normally consider inappropriate to commodify, such as the exploitation of human workers [16]. The third effect is that neoliberalism fosters a continuallygrowing intimacy between corporate and financial capital within the state, which leads to corporatecontrolled decisions about politics and economics. Finally, neoliberalism wreaks economic havoc by destabilizing or causing dramatic fluctuation in financial markets [5].

We examine how neoliberal ideology affects experience in online games, focusing on two of the four effects that Brown discusses: intensified inequality between social classes and the unethical commercialization of human workers [5]. These two effects exemplify behavioral patterns in the governance of collaborative activities and social interactions between players in WoW and Nostalrius. We acknowledge that this is a difficult assertion to make. However, too often broader cultural and economic influences are overlooked in studies of online communities $[17,18]$. We argue that it is important to consider wider cultural and sociopolitical influences when examining social lives online. Neoliberal values most closely mirror the behaviors we saw on Nostalrius, and thus, we use this theoretical framework to analyze players' experiences. While the design of the game is influenced by cultural ideologies, the current paper focuses the ways that the players, not the game, are influenced by and embody neoliberal values (see $[8,19]$ for further analysis of WoW's design).

\section{Methods}

We conducted an ethnographic investigation of the Nostalrius Begins private server from April 2015 to February 2016. Our methods follow Boellstorff et al.'s [3] guidelines for ethnographic inquiry in virtual worlds. Participant-observation included playing the game, joining guilds of players, reading the official forums for the server, reading guild forums, reading strategic guides for raids and boss fights, and spending time with two North American guilds, "Roasted Quail" and "Impetus" (pseudonyms). We refer to the "guild leadership," a core of six to eight players who collectively decided on issues of governance for the guild. While there were some fluctuations in leadership over the year of play (the first author was a member of the leadership for several months), two of the main, and most influential members, were in positions of power throughout the period of research. We recorded screenshots, chatlogs, in-game mail, and video streams (via Twitch.tv). Terminology, such as 20- and 40-man raid, are emic terms that the players themselves used to discuss activities and events, and we adopt these terms are they are universally used in World of Warcraft.

We conducted semi-structured, audio-taped interviews with eight players from the two guilds. Interviews took place remotely via the VOIP program Skype and were recorded using MP3 Skype Recorder. Interviews and ethnographic data were analyzed by all three authors with grounded theory [41], using axial coding. The authors discussed themes to capture the richness of the data and find reliable interpretations.

\section{Results}

We argue that affordances alone do not determine social experience in online games. In our study, affordances interacted with the wider ideology of offline culture in which players are immersed, creating a tension between community and competition. Players reported experiencing an overall decline in social experience on Nostalrius, even though they had hoped to return to the "glory days."

\subsection{Community on Nostalrius Begins}

For many players, entering Nostalrius Begins was an exciting and nostalgic experience: "I'm sure anyone 
who could read the name would tell, like the nostalgic feeling of something you loved that was taken away. And to have that back is just insane." Some of this nostalgia came from re-experiencing old areas of the game, such as dungeons and questing areas. But social interactions with others were another major contributor to the nostalgic experience. One player explained the role that chat channels had in her play experience:

"I really like the banter in the general chat channels, even The Barrens [a notorious chat locale]...it's something to keep you awake and make you laugh at the absurdity of it. I had really missed that as it phased out of retail WoW, so it was fun to see people actually talking to each other again...[when retail] channels were empty. You were very much 'alone' unless you initiated everything."

In this player's estimation, even The Barrens chat, a zone of lewd and crude discussions, contributed to the play experience. It kept her alert while questing in the game world, and contributed to a feeling that the people she played with were, in fact, people. This type of social experience, she argued, was absent from the current version of retail WoW.

The players we talked to originally met in Roasted Quail, a small, tight-knit raiding guild. The goal of the guild was to experience old raid content with a group of competent, friendly, and mature raiders with leaders who had played retail WoW together. Though small, guild members were frequently online looking for dungeon groups, trying to improve their gear for upcoming raids, and sometimes just sitting around to talk with each other:

"It's a place where...you get a chance to interact with a bunch of people you wouldn't have otherwise interacted with...It's just a place you can go to meet people and interact with people where you have like, a common goal. It just gives you an opportunity to, I don't know. Socialize."

Roasted Quail was determined to experience all the content in the game. As Roasted Quail defeated more bosses, they were rewarded with rare equipment to help them attempt new and more difficult challenges. Progress continued, and Roasted Quail began to develop a name for themselves on the server as a successful raiding guild.

\subsection{A New Guild and New Ideology}

However, progress eventually turned to stagnation. In December 2015, Roasted Quail defeated the last boss of Blackwing Lair, completing all of the content that was available. Now the guild leadership began to focus on efficiency. Several measures were put forward as important: reducing the time needed to kill each boss, reducing the idle time between fights, and increasing damage and healing output from raiders. Though raids were successful, the guild sometimes struggled to fill a 40-man raid, which meant attempting fights with fewer players. While these sub-optimal raid groups could still defeat bosses, they could not do so to the new standards that the guild leadership promoted.

To combat this problem, the Roasted Quail leadership decided to merge with another small North American raiding guild, Rumble Raiders, creating a new guild called Impetus. This merger became the basis for much of the strife that plagued Impetus in the months to come (see [33] for an analysis of guild alliances). As its name implies, Impetus focused on high-speed, efficient runs, without as much concern for sociality within the guild. This shift in priorities did not go unnoticed by the former members of Roasted Quail:

"[The leadership] felt that the guild was underperforming for the amount of gear and progression that we were accomplishing, so they decided to expand the roster, make raid slots more competitive so that people would try harder...They wanted people to not feel safe and secure."

Many players began working harder to make sure that they were performing well in raids to secure their place in upcoming groups. A guild roster that could barely fill a 40-man raid now had between 70-80 potential raiders, creating severe competition for spots. A spirit of competition, coupled with new, unfamiliar members, changed the guild atmosphere dramatically:

"It's not the same atmosphere...as Roasted Quail, where like 'Oh we're raiding with,' like I was going to say 'family' right? It wasn't really a family, but people got along pretty nicely, and I can't tell you one person that I disliked in Roasted Quail. I just can't. I think I pretty much liked everyone. In Impetus it's like, they try to pick the best from each and every little sub-group, so the atmosphere is competition, it's not that it's a negative effect...but it's not the same friendly atmosphere."

As time went on, the leadership solidified a new core of raiders based on who was performing well according to metrics collected by RealmPlayers. This method of creating a raid roster had profound effects on the guild. First, some players who had romantic partners or friends with whom they played were no longer able to raid together if others with whom they had formerly played were not performing well. For example, a married couple from Roasted Quail were regularly separated for Impetus raids when the husband was invited, but the wife was "benched" in favor of other, better performing players. While the couple began playing on Nostalrius to spend time together, the prioritization of efficiency prevented them from raiding together. Second, some players from Roasted Quail began to feel that the leadership was overlooking 
the help they provided the guild in previous content. Before the merger, Rumble Raiders had five bosses that they had not yet defeated. In the new raid roster, some original members of Roasted Quail were replaced by members of Rumble Raiders. Once the new raid group was formed, some players who did not make the cut stopped logging on for raids entirely, often because they knew they would not be invited to the group. In creating competition for raid spots, the leadership had unintentionally pushed many of their raiders away from the game. This problem became evident one night when two members of the raid made mistakes on a particular boss fight:

"I think one [person] died first and then [more mistakes] happened and they just called it, and they kicked them too! They kicked [a warrior] and whoever the mage was. Like because they made a mistake. Like that's ridiculous to me...We're supposed to have people on standby, but you know, you don't get an invite to a raid, you're not staying on to just watch everyone else get loot. You're logging [off]. You're doing something else. So there was no one waiting, [and] they just got kicked and that was it. They just sat out. Like, they got put in time out outside of the [dungeon]. And that was it."

Changing the atmosphere of the guild to one of competition, rather than, as one player mentioned, "a family," had detrimental effects on both the social interactions between guild members and progression in raids. Some players felt disenfranchised by the leadership, isolated from their peers, and devalued as persons during raids.

\subsection{RealmPlayers and Neoliberalism}

After the creation of Impetus, the guild leadership used RealmPlayers' data to determine who the strongest and weakest members of the two former guilds were. The leaders established a new raiding roster comprised of the best performing players.

However, RealmPlayers is not robust enough to record every single action a player takes. In fact, many abilities are ignored in the RealmPlayers algorithm. The omissions were distressing to affected players. For example, one player said:

"What I wish happened was meters showing like dispels, cleanses, them showing spell interrupts, you know stuff like that. It doesn't, so all you get is people who just spam their highest [damage] stuff and get on the meters."

As this player notes, RealmPlayers does not record abilities that do not do any quantifiable damage, such as "dispels" and "cleanses." Many players avoided using these kinds of supportive abilities in favor of maximizing their damage or healing output. But refusing to use these abilities caused problems in raid dynamics. Raids are designed so that these abilities must be deployed in order to defeat bosses. Situations where players unintentionally led to the death of members of their raid group by refusing to use nonquantifiable skills and abilities became more prevalent in raids. While the neoliberal ideology prescribes ubiquitous quantification, not everything is quantifiable. With RealmPlayers functioning as the focal point for determining who did and did not receive an invite to future groups, players were only concerned with how much damage or healing they generated during raids. The limitations of RealmPlayers and the limitations of quantitative data created a tension between players wanting to perform well on the meters and players actually performing well in the raids.

One player reflected on his experience watching RealmPlayers dominate raid choices:

"It...ignores too much else, like it creates bad incentives. Like, there's times when we say '[damage] stop. Stop [damage].' But then people keep [doing damage]. And there's a reason for that. Because they get rewarded for it...[but] people have other responsibilities, like for example, [another player said:] 'Oh I don't want [that role] because I want to be able to just sit there and do damage so I can be higher on the meters."

This player felt that RealmPlayers provided "bad incentives" for player behaviors. In some situations, all members of the raid need to stop attacking a boss to prevent particular negative outcomes, such as special attacks, that could kill the raid group. However, some players felt that they could sneak in a few extra attacks to improve their ranking on RealmPlayers without the leadership noticing. These players sometimes accidentally led to the death of all 39 other players in the raid in order to improve their damage for the fight!

RealmPlayers had detrimental effects outside raids too. In an effort to improve the guild's ranking on the leader board, Impetus leadership removed alternate or "alt" characters (secondary characters to supplement a player's "main" character) and social players (members who did not actively raid or just had friends in the guild) from the guild roster. One player said:

"RealmPlayers ranks the guilds by boss kills. They were seeing if fewer [non-raiders at the level cap of 60], and thus a higher percentage of guild [members] listed on boss kills, made a difference in the guilds rankings. Spoiler: it doesn't really make a huge difference, but that experience was extremely annoying."

As the player mentioned, this experiment was solely to improve the guild's ranking. However, it created problems for guild members. All alts were removed from the guild for this experiment, which 
meant that many players who were leveling had no access to guild chat. All of these changes contributed to problems in communication between members of the guild, raider or otherwise. One player noted:

"If the alt isn't in guild, I can't keep an eye on g[uild] chat for a group, or just banter with them while leveling... [for example] let me switch to [my main character] and help you XYZ, whether it's helping one person do something, or joining a group for a dungeon."

For this player, group activities became much harder to coordinate since while she was on her alt, she was unable to see what other guild members were doing or coordinate with them via chat. Over time, some players began to leave:

"Well, there's been a bit of, like, sort of a pessimistic mood about how the guild has been going. And like, they recently made it so that alts couldn't join the guild, and they're like trying to boost their RealmPlayers status and everything...I feel like they're realizing that they're losing players. That their core is sort of weakening and everything."

Players' reasons for leaving varied, but a portion of players left because of the change in the guild's atmosphere. The aloofness of the guild leadership contributed to many players' anxieties. Often during raids, players would chat with the first author privately about the lack of transparency from the guild leadership and lack of responses to concerns from raiders. One player, who left Impetus after regularly being overlooked for raids, made a distinction between "old school" and "new school" WoW:

"And so the old school WoW mentality says like, that there's like loyalty there, there's like everything: you're finishing the [dungeons], you're killing the bosses, that's what's important and you're doing it with a group of people who...give a shit about you...Even if it takes longer, whatever. And the new school WoW mentality is that this person does 10 [damage] more than you per second on this boss fight, and net/net there's no difference, like net/net we're still killing the boss, it just will take like, you know 3 minutes less time or whatever, if everybody in our raid does 10 [damage] more...[but being good is] not like, metrics driven, like what you're doing is not driven by like metrics or healing meters. It's driven by like success in the raid, you know?"

As this player pointed out, Impetus' new atmosphere was similar to what he referred to as "new school WoW." The shift from valuing "loyalty" to valuing efficiency and quantifiable metrics left many players feeling that they had been abandoned by their guild. At the time we ended ethnographic data collection, roughly half of Roasted Quail's original core team had left Impetus or left Nostalrius entirely.

\subsection{Nostalrius Ends}

On April 6, 2016, the Nostalrius Begins home page was changed to an open letter to the community:

"Yesterday, we received a letter of formal notice from US and french [sic] lawyers, acting on behalf of Blizzard Entertainment, preparing to stand trial against our hosting company OVH and ourselves in less than a week now. This means the de facto end of Nostalrius under its current form...Nostalrius Begins ...will be definitively shutdown at 23:00 server time on the 10th of April 2016" [50].

The announcement was coupled with a promise to release the source code and anonymized player data so that Nostalrius members could continue to foster the community scene on their own, and subvert the control that Blizzard was trying to exert over the players.

After the announcement of the server's imminent shut down, we began to see signs of community reappearing. Members of Nostalrius Begins began working to preserve their social relationships after the imminent shutdown was announced. For example, even in Impetus, where the raiding atmosphere had shifted to more neoliberal practices, players were trying to figure out where to go to could continue playing together. One member of the leadership even created a poll to make a democratic decision about where the guild would move based on overall interest.

On April $10^{\text {th }}$, Nostalrius players were to be stranded without their characters, without their server, and without a stable means of communication. The Nostalrius community was livid. Global in-game chat channels were flooded with comments from disgruntled players. Some demonized Blizzard: "NOT A PENNY OR A SHEKEL WILL WE GIVE TO BLIZZARD EVER AGAIN." One player said: "So, who's up for heading to Activision Blizzard $H Q$ and rolling some heads?" Others advertised different private servers, encouraging Nostalrius players to join in order to preserve the community in a new venue:

"FIGHT THE VANILLA FIGHT JOIN KRONOS HOLD ONTO THE VANILLA DREAM JOIN A NEW JOIN KRONOS TODAY AT KRONOS.COM EASY AS PIE CHANGE UR REALM LIST AND UR RADY [sic] TO START!"

Nostalrius players bombarded the World of Warcraft and Blizzard official Facebook pages with comments. Every company post was met with dozens, and frequently, hundreds, of comments from angry players protesting Blizzard's decision to take their server away. Despite the prevalence of neoliberal values, once the sever was threatened, players banded together to fight against what they saw as unjust and unfair governance of their gaming experience. This 
development was unexpected by both us as researchers, and by Blizzard itself. Blizzard ignored many of the comments and posts on their sites, but continued pressure from the community and considerable mainstream and gaming news coverage prompted an official statement from J. Allen Brack, Vice President for Blizzard and Production Director for World of Warcraft, on April 26th:

"We wanted to let you know that we've been closely following the Nostalrius discussion and we appreciate your constructive thoughts and suggestions. Our silence on this subject definitely doesn't reflect our level of engagement and passion around this topic. We hear you...You, the Blizzard community, are the most dedicated, passionate players out there. We thank you for your constructive thoughts and suggestions. We are listening. " [51]

Though no action has been taken to reinstate Nostalrius, or to offer an alternative, this post was the beginning of a dialogue between Blizzard and the player community that they had alienated in their decision to shut down Nostalrius.

\section{Discussion}

The World of Warcraft of today is different from the World of Warcraft released in 2004. While a capitalist company created the game in a capitalist society, there was an era where socialist values were more evident in game play. Players were required to rely on each other to improve their characters and complete game content. Certain classes were near impossible to play alone, and certain challenges could not be completed without help from others. Before changes to the game that automated group finding processes [8], much of the game's content was inaccessible without some social interaction.

The hyper-quantified, neoliberal way of approaching the game that grew within Impetus has been present in hardcore gaming circles since Vanilla WoW [4,14,29,32,39]. But this approach to the game was not as prevalent as it is today. Braithwaite [4] explains that Blizzard has changed the focus of the game to "emphasize individual achievement rather than collaborative effort." In Vanilla WoW and in the early expansions, players participated in informal acts of fun, organized structured raid events, and created robust social communities [1,11,12,28,29,30,32,38,43]. Past research indicates that players used the game to support real-life relationships, form new, online relationships, and socialize with individuals who they might never have the chance to meet face to face.

Because RealmPlayers was not required, some members of Impetus suggested ignoring it, or not using it in raids. One player who had a leadership role said: "Some officers actually floated that idea of not recording [RealmPlayers information], but then they said 'Well, people are going to record anyway." Players who regularly ranked highly on RealmPlayers were incentivized to continue collecting data on their performance because it ensured that they would maintain their raid spot in the future. Despite what the leadership may have asked, if even one player in the 40-man raid decided to use RealmPlayers, quantified information about individual performance in the raid would be available. Though the system did not have to be used, some players preferred to use it. Leader boards and other ranking systems like RealmPlayers are consistent with neoliberalism, allowing players to quantify their performance in comparison to their peers, to make value judgments about other players according to their ranking on the meters, and to encourage people to focus on their own actions, even when those actions detract from the overall success of the group. As players became more reliant on evaluating their worth to the guild as indicated by their numbers on RealmPlayers, the social community of the guild suffered.

However, this was not the end of community on Nostalrius Begins. After the announcement of the server shut down, community began to re-emerge. This development parallels Poor and Skoric's [35,36] findings on sociality in long-term online communities which reports that people who played together for extended periods were more likely to stay together in multiple settings, such as changes between guilds [35] or changes between game spaces [36]. There was an underlying community on Nostalrius Begins that asserted itself when the server was threatened. But why did it take so long and require a particular crisis event? We argue that many online gaming communities struggle with a tension between community and competition. Many popular game titles introduce this tension through the design of the game through narrative conflict [14], requiring that players work together to achieve a common goal, but by also rewarding those players who perform particularly well, even if their performance harms a team effort as we saw with Impetus raids. Nardi [29] documented similar behavior in WoW when raid sizes changed from 40man to 20-man raiding. Fewer raid slots meant higher competition for the available positions. In most cases, these tensions lead to guilds fracturing and segmenting - often based on the skill level of the players, rather than the social relationships that had been built within the guild.

But many players still want a social experience from the games they play. Players reminisce, for example, about Vanilla WoW because of the sense of 
the community and the social interactions [4,8,32]. However, having the ability to track performance through quantifiable metrics can conflict with players' motivations for social interaction. Instead of viewing other players as social agents with whom to communicate and collaborate, other players become neoliberal objects: things to compete against, tools to improve the effectiveness of the raid group, cogs in a machine whose purpose is to facilitate a player's needs.

Our examination of social life on the Nostalrius Begins server indicates that while games are products of the cultures they emerge from, so are the players. Game design is only one contributor to social experience in online games. In the case of the use of RealmPlayers on Nostalrius Begins, the people, not the game, perpetuated a system that valued players for their quantified contributions, rather than for their roles as fully realized social beings. This competitive outlook is consistent with attitudes in retail WoW and wider gaming culture, but conflicts with the sense of community that was embraced in earlier versions of the game $[4,8,32]$. Interaction on World of Warcraft happens through a variety of relations: player-to-player relationships, guild-to-guild relationships, server-toserver relationships, player-to-developer relationships, and private server developer-to-retail server developer relationships, to name a few. However, it is important to note that all of these relationships are framed within a neoliberal society and influenced by neoliberal ideologies in ways that affect individual and group behaviors. While previous research and the player community's own nostalgia identifies Vanilla as the glory days of World of Warcraft, people are still tempted and incentivized by systems that cater to neoliberal values.

We acknowledge the potential difficulties in using neoliberalism as a framework because of the broad interpretive scope required. However, while cultural and economic influences are difficult to discuss and analyze, we argue that they are important discussions that need to happen. Our use of the neoliberal framework in this context is applicable because both guilds studied were comprised of North American players. However, it is possible that differences in offline culture could contribute to differences in online behaviors [20,27]. Though the present study is not comparative, it offers important insights regarding the effects of offline culture on online practices.

\section{Conclusion}

We examined the ways that the neoliberal ideology of wider, Western culture emerges through the interaction between technologies and the people who use them. It is important to continue to examine the influence of offline culture to make more accurate claims about our research in online communities. We analyzed players' use of RealmPlayers, a software modification that allowed players to track their performance, but also encouraged competition rather than cooperation.

While Nostalrius Begins originally intended to bring back a nostalgic, Vanilla WoW experience, players were influenced by the neoliberal ideology that encouraged them to see each other as competitors rather than collaborators. The tension between community and competition more closely matched current versions of retail World of Warcraft, rather than the game version that many players were trying to re-experience by playing on Nostalrius.

After the announcement that the server would be shut down, we began to see elements of community reemerging as players protested Blizzard's actions to abolish the server's existence. We plan to examine the circumstances surrounding Nostalrius Begins' closure to further explore issues of governance and sociality in online games.

\section{References}

[1] Bardzell, S., Bardzell, J., Pace, T., and Reed, K. Blissfully productive: grouping and cooperation in world of warcraft instance runs. Proc. of CSCW, ACM (2008).

[2] Bergstrom, K., Carter, M., Woodford, D., and Paul, C. Constructing the ideal EVE online player. Proc. of DiGRA, (2013).

[3] Boellstorff, T., Nardi, B., and Pearce, C. Ethnography and virtual worlds: A handbook of method. Princeton University Press, 2012.

[4] Braithwaite, A. WoWing Alone The Evolution of "Multiplayer" in World of Warcraft. Games and Culture, (2015).

[5] Brown, W. Undoing the Demos: Neoliberalism's Stealth Revolution. MIT Press, 2015.

[6] Consalvo, M. Players and Their Pets. University of Minnesota Press, 2015.

[7] Consalvo, M. and Begy, J. What Happens at the End of the World? An MMOG's Closure and Player Responses. (2012).

[8] Crenshaw, N. and Nardi, B. "It Was More than Just the Game, It Was the Community": Affordances in Social Games. Proc. of HICSS, (2016).

[9] Dabbish, L., Kraut, R., and Patton, J. Communication and Commitment in an Online Game Team. Proc. of CHI, ACM (2012).

[10] Debeauvais, T. and Nardi, B. A qualitative study of Ragnarök Online private servers: in-game sociological issues. Proc. of FDG, ACM (2010).

[11] Ducheneaut, N. and Moore, R.J. The Social Side of Gaming: A Study of Interaction Patterns in a Massively Multiplayer Online Game. Proc. of CSCW, ACM (2004), 360-369. 
[12] Ducheneaut, N., Moore, R.J., and Nickell, E. Virtual "Third Places": A Case Study of Sociability in Massively Multiplayer Games. Computer Supported Cooperative Work 16, 1-2 (2007).

[13] Dutton, W.H. Information and Communication Technologies: Visions and Realities. Oxford University Press, Inc., New York, NY, USA, 1996.

[14] Dyer-Witheford, N. and de Peuter, G. Games of Empire: Global Capitalism and Video Games. Minneapolis: University of Minnesota, (2009).

[15] Ekbia, H. and Nardi, B. Inverse instrumentality: How technologies objectify patients and players. Oxford: Oxford University Press, 2012.

[16] Ekbia, H. and Nardi, B. Heteromation and its (dis)contents: The invisible division of labor between humans and machines. First Monday 19, 6 (2014).

[17] Ekbia, H. and Nardi, B. The political economy of computing: the elephant in the HCI room. Interactions 22, 6 (2015).

[18] Ekbia, H. and Nardi, B. Social Inequality and HCI: The View from Political Economy. Proc. of CHI, ACM (2016).

[19] Eklund, L. and Johansson, M. Played and designed sociality in a massive multiplayer online game. Eludamos. Journal for Computer Game Culture 7, 1 (2013).

[20] Feng, J. From role play to behavior: How cultural background influences Western and Eastern MMOG players in world of warcraft. (2014).

[21] Feng, W., Brandt, D., and Saha, D. A Long-term Study of a Popular MMORPG. Proc. of SIGCOMM Workshop on Network and System Support for Games, ACM (2007).

[22] Foucault, M. The birth of biopolitics: lectures at the Collège de France. Palgrave Macmillan New York, 1979.

[23] Friedman, M. Capitalism and Freedom. University of Chicago Press, 1962.

[24] Irani, L.C. and Silberman, M. Turkopticon: Interrupting worker invisibility in amazon mechanical turk. Proc. of $\mathrm{CHI}$, ACM (2013).

[25] Klein, H.K. and Kleinman, D.L. The Social Construction of Technology: Structural Considerations. Science, Technology \& Human Values 27, 1 (2002), 28-52.

[26] Kow, Y.M. and Nardi, B. Culture and creativity: World of Warcraft modding in China and the US. In Online worlds: Convergence of the real and the virtual. Springer, 2010.

[27] Lindtner, S., Mainwaring, S., Dourish, P., and Wang, Y. Situating productive play: Online gaming practices and guanxi in China. IFIP Conference on Human-Computer Interaction, Springer (2009).

[28] Moore, R.J., Ducheneaut, N., and Nickell, E. Doing virtually nothing: Awareness and accountability in massively multiplayer online worlds. Computer Supported Cooperative Work 16, 3 (2007).

[29] Nardi, B. My Life as a Night Elf Priest: An Anthropological Account of World of Warcraft. University of Michigan Press, Ann Arbor, 2010.

[30] Nardi, B. and Harris, J. Strangers and friends: Collaborative play in World of Warcraft. Proc. of CSCW, ACM (2006).
[31] Nardi, B. and Kallinikos, J. Technology, agency, and community: The case of modding in World of Warcraft. Industrial informatics design, use and innovation, (2010).

[32] O'Connor, E.L., Longman, H., White, K.M., and Obst, P.L. Sense of Community, Social Identity and Social Support Among Players of Massively Multiplayer Online Games (MMOGs): A Qualitative Analysis. Journal of Community \& Applied Social Psychology, (2015).

[33] Paul, C.A. and Philpott, J. The Rise and Fall of CTS: Kenneth Burke Identifying with the World of Warcraft. Proc. of DiGRA, (2009).

[34] Piketty, T. Capital in the twenty-first century. Harvard University Press, 2014.

[35] Poor, N. and Skoric, M. Play Together, Stay Together? Community Cohesion and Stability in an MMO. Proc. of HICSS, IEEE (2016).

[36] Poor, N. and Skoric, M.M. Death of a Guild, Birth of a Network Online Community Ties Within and Beyond Code. Games and Culture 9, 3 (2014).

[37] Scacchi, W. Computer game mods, modders, modding, and the mod scene. First Monday 15, 5 (2010).

[38] Schiano, D.J., Nardi, B., Debeauvais, T., Ducheneaut, N., and Yee, N. A New Look at World of Warcraft's Social Landscape. Proceedings of the 6th International Conference on Foundations of Digital Games, ACM (2011).

[39] Silverman, M. and Simon, B. Discipline and dragon kill points in the online power game. Games and Culture 4, 4 (2009).

[40] Stiglitz, J. Is Inequality Inevitable? The New York Times, 2014. http://opinionator.blogs.nytimes.com/.

[41] Strauss, A. and Corbin, J. Grounded theory methodology. Handbook of qualitative research, (1994).

[42] Taylor, N., Bergstrom, K., Jenson, J., and de Castell, S. Alienated playbour relations of production in EVE Online. Games and Culture, (2015).

[43] Williams, D., Ducheneaut, N., Xiong, L., Zhang, Y., Yee, N., and Nickell, E. From tree house to barracks the social life of guilds in World of Warcraft. Games and culture 1,4 (2006).

[44] Williams, R. and Edge, D. The social shaping of technology. Research Policy 25, 6 (1996).

[45] Winkie, L. The People Who Still Play World of Warcraft Like It's 2006. Kotaku, 2015. http://kotaku.com/.

[46] Yee, N. The demographics, motivations, and derived experiences of users of massively multi-user online graphical environments. Presence 15, 3 (2006).

[47] Yee, N. The Proteus Paradox: How Online Games and Virtual Worlds Change Us-and how They Don't. Yale University Press, 2014.

[48] MMO-Champion - WoW Down to 5.5 Million Subscribers, Warcraft Movie Trailer at Blizzcon. http://www.mmo-champion.com/.

[49] RealmPlayers. http://realmplayers.com/.

[50] Nostalrius Begins. https://en.nostalrius.org/.

[51] To the WoW Community -. World of Warcraft. http://us.battle.net/. 